\title{
Effect of nano-zinc oxide and fluoride-doped bioactive glass-based dentifrices on esthetic restorations
}

\section{Wpływ past do zębów zawierających tlenek nano-cynku oraz bioaktywne szkło z fluorkami na estetyczne materiały wypełniające}

\author{
Abdulelah Ali AlSubaie ${ }^{1, B-D}$, Zenab Sarfraz ${ }^{2,3, B, C}$, Abdulhadi Ahmed AlAli ${ }^{1, B-D}$, Abdulmohsen Essa AlEssa, ${ }^{1, B, C}$, Hassan Ali Al Subaie ${ }^{1, B-D}$, \\ Asma Tufail Shah ${ }^{2, A, E}$, Abdul Samad Khan ${ }^{1, A, C-F}$ \\ ${ }^{1}$ Department of Restorative Dental Science, College of Dentistry, Imam Abdulrahman Bin Faisal University, Dammam, Saudi Arabia \\ ${ }^{2}$ Interdisciplinary Research Centre in Biomedical Materials, COMSATS University Islamabad, Lahore Campus, Lahore, Pakistan \\ ${ }^{3}$ Department of Dental Materials, Akhtar Saeed Medical and Dental College, Lahore, Pakistan \\ A - research concept and design; $\mathrm{B}$ - collection and/or assembly of data; $\mathrm{C}$ - data analysis and interpretation; \\ $D$ - writing the article; $E$ - critical revision of the article; $F$ - final approval of the article
}

Address for correspondence

Abdul Samad Khan

E-mail: akhan@iau.edu.sa

Funding sources

None declared

Conflict of interest

None declared

\section{Acknowledgements}

The authors would like to acknowledge Dr. Aqif Anwar Chaudhry

for providing zinc oxide nanoparticles and Mr. Lindsey

from Biomaterials Research Laboratory, College of Dentistry,

Imam Abdulrahman Bin Faisal University, Dammam,

Saudi Arabia for facilitating the experimental analysis.

Received on November 30, 2018

Reviewed on January 5, 2019

Accepted on February 1, 2019

Published online on March 29, 2019

Cite as

Alsubaie AA, SarfazZ, AIAli AA, et al. Effect of nano-zinc oxide and fluoride-doped bioactive glass-based dentifrices on esthetic restorations. Dent Med Probl. 2019;56(1):59-65. doi:10.17219/dmp/103597

D0I

$10.17219 / \mathrm{dmp} / 103597$

Copyright

○ 2019 by Wroclaw Medical University

This is an article distributed under the terms of the

Creative Commons Attribution Non-Commercial License

(http://creativecommons.org/licenses/by-nc-nd/4.0/)

\section{Abstract}

Background. Over time, improvements have been made in dentifrices and recently bioactive components have been added. It is important to address the abrasivity of these dentifrices, which can cause wear of dental restorative materials.

Objectives. A comparative study was conducted to examine the effects of commercial and experimental dentifrices upon commonly used dental restorative materials.

Material and methods. Three types of experimental dentifrices were prepared with variable concentrations of fluoride-based bioactive glass, nano-zinc oxide $(\mathrm{ZnO})$ and titanium dioxide $\left(\mathrm{TiO}_{2}\right)$ powder as active ingredients. A custom-made toothbrush simulator was used with variable cycles $(0 ; 5,000$; and 10,000) to treat samples prepared from dental restorative materials. Prior to and after the treatment cycles, the physical properties of the restorative materials were assessed and compared with commercial toothpaste through micro-hardness, surface roughness and color stability testing.

Results. The restorative materials showed an insignificant difference in terms of micro-hardness before and after the treatment with all dentifrices. A significant difference was observed in terms of surface roughness. With respect to color stability, there has been observed an insignificant difference between the control and the other 3 experimental dentifrices for all the cycles - pre, post-5,000 and post-10,000.

Conclusions. Experimental fluoride-containing bioactive dentifrices caused a change in the restorative material properties; however, it was minimal and the properties still met the requirements for clinical applications.

Key words: zinc oxide, dentifrices, dental composites, fluoride-bioactive glass, resin-modified glass-ionomer cement

Słowa kluczowe: tlenek cynku, pasty do zębów, kompozytowe materiały dentystyczne, bioaktywne szkło z fluorkami, modyfikowany żywicą cement szkło-jonomerowy 


\section{Introduction}

Since the introduction of restorative materials to the dental field, a paradigm shift has been observed toward esthetic dentistry, and due to the esthetic demands, more emphasis has been put on color-, shade-, texture-, and shape-matching materials, like resin-based composites (RBCs). ${ }^{1}$ Resin-based composites have been used to restore damaged, aged and traumatized teeth. ${ }^{2}$ The physical and mechanical properties of esthetic restorative materials provide an indication of how the material will behave in the oral environment. While using these materials, an important property to be considered is surface roughness. This property has a high impact on the quality of the esthetic restoration in terms of color stability and gloss. ${ }^{3}$

Tooth brushing is considered a significant factor in improving oral health ${ }^{4}$; on the other hand, some untoward effects of using a toothbrush and dentifrices on color stability and surface roughness have been observed. ${ }^{5-8}$ It has been reported that brushing increases the surface roughness and subsequently leads to plaque accumulation.,9,10 What has to be taken into consideration is the abrasiveness of the dentifrice. Some studies have claimed that dentifrices might cause the deterioration of restorative materials. ${ }^{8,11}$ The size of particles and the type of abrasive agents used have an influence on the abrasiveness of the dentifrice. ${ }^{5,12}$

A desire to improve the quality of oral hygiene has given rise to many types of dentifrices. Experimental toothpaste, containing $5 \%$ calcium sodium phosphosilicate has shown a positive effect with regard to the reduction in sensitivity. ${ }^{13}$ A comparative in vitro study showed that calcium sodium phosphosilicate-based dentifrices (i.e., NovaMin ${ }^{\circledR}$; GSK, Brentford, UK) showed a significant increase in microhardness and a decrease in surface roughness of the tooth structure. ${ }^{14}$ The bioactive glass material has been used in toothpaste to impart some advantages, such as dentinal tubule occlusion and the remineralization effect. It has been observed that the addition of bioactive glass (45S5 bioglass) affects the subsurface and surface erosion of the enamel by improving the micro-hardness of the enamel. ${ }^{15}$ However, the $45 \mathrm{~S} 5$ bioglass used in the toothpaste was harder than the enamel tissue; therefore, it could wear the enamel. ${ }^{16}$ Another study has reported that the DP-bioglass toothpaste has a considerable effect on reducing sensitivity by sealing dentinal tubules. ${ }^{17}$

Fluoridated toothpaste plays a positive role in preventing dental caries and the remineralization effect on the early stages of a carious lesion, and subsequently, it can slow down the demineralization process. ${ }^{18}$ The fluoride ions can inhibit the production of bacterial acids in dental plaque by changing the metabolic process of bacterial flora. ${ }^{19}$ Zinc oxide $(\mathrm{ZnO})$ is known for its anti-gingivitis and bactericidal effect. ${ }^{12,20}$ Dentifrices containing $\mathrm{ZnO}$ have also been demonstrated to have a positive effect on the dentin by reducing demineralization. ${ }^{21}$ Moreover, due to its antibacterial and anti-gingivitis action, zinc $(\mathrm{Zn})$ has been incorporated into bioactive glass dentifrices, and it is suggested that increasing the content of $\mathrm{Zn}$ in dentifrices could result in a better antibacterial and anti-gingivitis effect. ${ }^{20}$

Fluoride-doped bioactive glass (F-BG) has recently been synthesized by our group and the long-term fluoride release behavior of F-BG as well as its effect on $\mathrm{pH}$ has been evaluated. ${ }^{22}$ Zinc oxide nanoparticles used in this study have been synthesized in our laboratory. ${ }^{23}$

The purpose of this study was to utilize F-BG (with $5 \mathrm{~mol} \%$ concentration of fluoride in bioactive glass), $\mathrm{ZnO}$ nanoparticles and titanium dioxide $\left(\mathrm{TiO}_{2}\right)$ as active agents in experimental dentifrices and compare their physical and mechanical effect on different restorative materials with a commercial dentifrice. Previously, bioactive glassbased dentifrices had been evaluated as a remineralizing agent on tooth surfaces. However, the authors could not find any study where any toothpaste containing bioactive glass had been applied on restorative materials and evaluated in terms of the surface roughness changes, microhardness and color stability. The null hypothesis was that the effect of experimental and commercial dentifrices on dental restorative materials would be the same.

\section{Material and methods}

In this study, 3 commercially used restorative materials were applied: Filtek ${ }^{\mathrm{TM}}$ Bulk Fill (3M ESPE, Seefeld, Germany), Filtek Z350 XT (nano-hybrid composite; 3M ESPE) and GC Fuji II LC (resin-modified glass-ionomer cement (RMGIC); GC Corp., Tokyo, Japan). The composition of these materials is given in Table 1. A commonly used commercial dentifrice, Colgate Advanced Whitening (Colgate-Palmolive Company, New York, USA) was used as the control (CT) and 3 experimental dentifrices, containing F-BG, $\mathrm{ZnO}$ nanoparticles and $\mathrm{TiO}_{2}$ powder as active ingredients, were synthesized in our laboratory. Initially, the basic ingredients were prepared, and then $\mathrm{TiO}_{2}(1.5 \%(\mathrm{w}))$ and $\mathrm{ZnO}$ nanoparticles $(3 \%(\mathrm{w}))$ were added. Fluoride-doped bioactive glass was used in various concentrations, i.e., $1.5 \%, 2.5 \%$ and $3.5 \%(\mathrm{w} / \mathrm{w})$, and the experimental dentifrices were denoted on the basis of these concentrations as ExpT-A, ExpT-B and ExpT-C, respectively. The composition of both the control and experimental dentifrices is given in Table 2 .

\section{Sample preparation}

The restorative materials were used as received, and samples were prepared according to the manufacturers' instructions. A total of 96 disc-shaped $(10 \mathrm{~mm}$ in diameter and $2 \mathrm{~mm}$ in height) samples of each group were prepared in a custom-made silicone mold. After being placed in a mold, the light-cured based restorative material samples were photoactivated using high-intensity LED blue light ( LITEX $^{\mathrm{TM}}$ 695C Cordless LED Curing Light; Dentamerica, Inc., City of Industry, USA), with the intensity 
Table 1. Frequency distribution of the root variations in the mandibular and maxillary second molars

\begin{tabular}{|c|c|c|}
\hline Restorative material & Company & Composition \\
\hline $\begin{array}{l}\text { Bulk-fill composite } \\
\text { (Filtek Bulk Fill) }\end{array}$ & $\begin{array}{l}\text { 3M ESPE, } \\
\text { Seefeld, Germany }\end{array}$ & $\begin{array}{l}\text { bis-GMA, UDMA, bis-EMA, and Procrylat resins; } \\
\text { fillers: zirconia/silica (a particle size range of } 0.01-3.5 \mu \mathrm{m} \text { and ytterbium trifluoride } \\
\text { filler (a particle size range of } 0.1-5.0 \mu \mathrm{m} \text { ); the inorganic filler loading is approx. } 64.5 \% \\
\text { (w) }(42.5 \%(\mathrm{v}))\end{array}$ \\
\hline $\begin{array}{l}\text { Nano-hybrid universal restorative } \\
\text { (Filtek Z350 XT) }\end{array}$ & $\begin{array}{l}\text { 3M ESPE, } \\
\text { Seefeld, Germany }\end{array}$ & $\begin{array}{l}\text { bis-GMA, UDMA, bis-EMA, PEGDMA, and TEGDMA resins; } \\
\text { fillers: surface-modified zirconia/silica (a median particle size - approx. } 3 \mu \mathrm{m} \text { or less), } \\
\text { non-agglomerated/non-aggregated } 20 \mathrm{~nm} \text { surface-modified silica particles; the filler } \\
\text { loading is } 82 \%(\mathrm{w})(68 \%(\mathrm{v}))\end{array}$ \\
\hline $\begin{array}{l}\text { RMGIC } \\
(\text { GC Fuji II LC) }\end{array}$ & $\begin{array}{l}\text { GC Corp, } \\
\text { Tokyo, Japan }\end{array}$ & $\begin{array}{l}\text { HEMA } 15-40 \% \text {, polybasic carboxylic acid 3-7\%, UDMA 1-5\%, dimethacrylate } 1-5 \% \\
\text { plus nonhazardous additions }\end{array}$ \\
\hline
\end{tabular}

bis-EMA - bisphenol A-diglycidyl methacrylate ethoxylated; bis-GMA - bisphenol A-diglycidyl methacrylate; HEMA - 2-hydroxyethyl methacrylate; PEGDMA - polyethylene glycol dimethacrylate; RMGIC - resin-modified glass-ionomer cement; TEGDMA - triethylene glycol dimethacrylate; UDMA - urethane dimethacrylate.

Table 2. Composition of experimental and commercial dentifrices

\begin{tabular}{|c|c|c|c|c|}
\hline Ingredients & Experimental dentifrice (A) & Experimental dentifrice (B) & Experimental dentifrice (C) & Commercial dentifrice \\
\hline Basic ingredients & & $\begin{array}{c}\text { glycerol } \\
\text { methylcellulose } \\
\text { calcium carbonate } \\
\text { sodium lauryl sulfate } \\
\text { flavoring agent } \\
\text { aqua (water) }\end{array}$ & & $\begin{array}{c}\text { sorbitol } \\
\text { hydrated silica } \\
\text { glycerin } \\
\text { sodium lauryl sulfate } \\
\text { polyethylene glycol } \\
\text { cellulose gum } \\
\text { xanthan gum } \\
\text { cocamidopropyl betaine } \\
\text { sodium saccharin } \\
\text { sodium hydroxide } \\
\text { limonene } \\
\text { flavoring agent } \\
\text { coloring agent } \\
\text { aqua (water) }\end{array}$ \\
\hline Active ingredients & $\begin{array}{c}\mathrm{F}-\mathrm{BG}(1.5 \%)+\mathrm{ZnO}(3 \%) \\
\mathrm{TiO}_{2}(1.5 \%)\end{array}$ & $\begin{array}{c}\mathrm{F}-\mathrm{BG}(2.5 \%)+\mathrm{ZnO}(3 \%) \\
\mathrm{TiO}_{2}(1.5 \%)\end{array}$ & $\begin{array}{c}\mathrm{F}-\mathrm{BG}(3.5 \%)+\mathrm{ZnO}(3 \%) \\
\mathrm{TiO}_{2}(1.5 \%)\end{array}$ & $\begin{array}{c}\text { sodium fluoride } 0.22 \% \\
\text { (1000 ppm fluoride) } \\
\text { penrasodium triphosphate } \\
\text { tetrapotassium pyrophosphate }\end{array}$ \\
\hline
\end{tabular}

F-BG - fluoride-doped bioactive glass; $\mathrm{TiO}_{2}$ - titanium dioxide; $\mathrm{ZnO}$ - zinc oxide.

of $1,200 \mathrm{~mW} / \mathrm{cm}^{2}$ and the wavelength of $470 \mathrm{~nm}$. The samples were placed on a glass slab and covered with a Mylar strip to avoid an oxygen inhibition layer, and were cured for $60 \mathrm{~s}$ from both sides. For RMGIC, the capsular type was used and properly condensed in a mold. After photoactivation, all samples were polished with alumina paste using a polisher (MetaServ ${ }^{\mathrm{TM}} 250$ Grinder-Polisher with Vector $^{\circledR}$ Power Head; Buehler, Lake Bluff, USA). The polished samples were sonicated and washed with water to remove any particles of the polishing paste. The samples of each material were divided into 4 main groups $(n=24)$ based on the dentifrices and prepared for pre-treatment analysis (microhardness, surface roughness and color stability testing). After this, the samples were treated with the dentifrices.

\section{Tooth brush simulation}

The groups of materials were subjected to each dentifrice in the toothbrush simulator ZM-3.8 (SD Mechatronik $\mathrm{GmbH}$, Feldkirchen, Austria). Prior to the start of testing, each dentifrice was mixed with distilled water at a 1:2 ratio ( $1 \mathrm{~g}$ of dentifrice to $2 \mathrm{~mL}$ water) to make a slurry. The slurry was applied to each toothbrush (manual, medium toothbrush; TARA Toothbrush Company, Dammam, Saudi Arabia). The prepared samples were put in a silicone mold and placed in an appropriate place. It was ensured that the samples contacted the toothbrush head once in each cycle. A load of $200 \mathrm{~g}$ was applied to the toothbrush head so that it contacted the samples; it was controlled by a central drive system. A total of 6 manual toothbrushes were placed and fixed in the holders, in which the head of the brush with its nylon bristles was seated perpendicular to the specimens, mounted at the same level, with the bristles touching the specimens without bending. Then, the machine was programmed to perform a complex motion. The reciprocation and speed were $2 \mathrm{~mm}$ and 160 cycles/min, respectively, up to 5,000 cycles (simulating 6 months). After that, the specimens were analyzed with regard to the 3 parameters - micro-hardness, surface roughness and color stability. Then, they were reinserted into the brushing machine to complete 10,000 cycles (simulating 1 year). The motion sequences were done by a programmed optional software module. After completing the cycles, the samples were examined again. 


\section{Vickers micro-hardness measurement}

Vickers micro-hardness value for all samples was evaluated using the MicroMet ${ }^{\circledR} 6040$ tester (Buehler) before and after the treatment cycles. The indent load was adjusted to $200 \mathrm{~g}$ and the dwell time was $10 \mathrm{~s}$. A total of 8 samples from each group were evaluated and 3 indents were taken on each sample.

\section{Surface roughness measurement}

To evaluate the 3D surface roughness before and after the treatment, 8 samples were examined using the Contour $^{\circledR}$ GT-K optical microscope (Bruker Optics, Inc., Billerica, USA) under the load of $50 \mathrm{~g}$ for $15 \mathrm{~s}$, with the vibration resistance, air isolation, time-tested properties, which provided an accurate result in terms of repeatability and quantity.

\section{Color stability measurement}

Regarding the evaluation of color stability, the Color-Eye ${ }^{\circledR}$ 7000A spectrophotometer (X-rite, Grand Rapids, USA) was used with the International Commission on Illumination (Commission internationale d'eclairage - CIE) $L^{*} a^{*} b^{*}$ based on the same illuminant against a black and white background ( $L^{*}$ refers to a gray degree corresponding to lightness; $a^{*}$ stands for the red-green axis; and $b^{*}$ for the blue-yellow axis). The spectrophotometer was used before and after the brushing simulating process for each group $(n=8)$. The calibration of the unit was performed before measurement according to the manufacturer's instructions. The color change $(\Delta E)$ was calculated using the following formula:

$$
\Delta E=\sqrt{\left(\Delta L^{*}\right)^{2}+\left(\Delta a^{*}\right)^{2}+\left(\Delta b^{*}\right)^{2}}
$$

where

$\Delta L^{*}, \Delta a^{*}, \Delta b^{*}$ represent differences in $L^{*}, a^{*}, b^{*}$, respectively, before and after brushing.

For statistical analysis, one-way analysis of variance (ANOVA) Tukey's post hoc test was used with IBM SPSS Statistics software v. 22 (IBM, Inc., Armonk, USA). For significant difference, the $p$-value was set at 0.05 .

\section{Results}

\section{Vickers micro-hardness measurement}

The micro-hardness results of all samples before and after the treatment are given in Fig. 1. The values for the resin-based composites (Filtek Bulk Fill and Filtek Z350 $\mathrm{XT})$ showed an insignificant difference $(p \geq 0.05)$ before

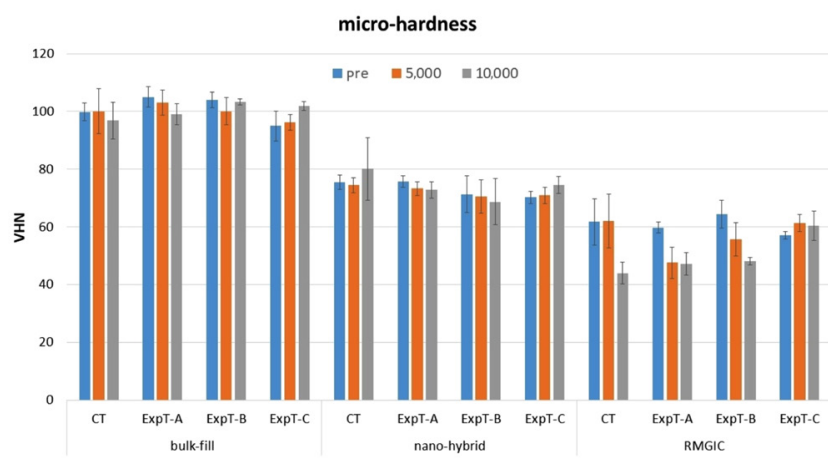

Fig. 1. Micro-hardness values of restorative materials before and after the treatment with commercial and experimental dentifrices

VHN - Vickers hardness number.

and after the toothbrushing treatment as compared to the control and all 3 types of experimental dentifrices. An insignificant difference $(p \geq 0.05)$ in the micro-hardness values was observed among the experimental dentifrices after the treatment with 5,000 and 10,000 cycles. For RMGIC (GC Fuji II LC), all dentifrice treatments showed a significant difference $(p \leq 0.05)$ in values, with the values decreased after the treatment.

\section{Surface roughness measurement}

The surface roughness was analyzed before and after the treatment, and the images of all groups are given in Fig. 2-4. The Ra values for all samples are given in Table 3. The surface roughness increased along with the treatment, and it was observed that the values for the resin-based composites (Filtek Bulk Fill and Filtek Z350 XT) and RMGIC (GC Fuji II LC) showed a significant difference $(p \leq 0.05)$ before and after the toothbrushing treatment as compared to the control and all 3 types of experimental dentifrices. Among these, RMGIC showed higher surface roughness compared to the resin-based composites, whereas the nano-hybrid composite showed the least. The change in the surface roughness values was irrespective of an increase in the concentration of F-BG in the experimental dentifrices.

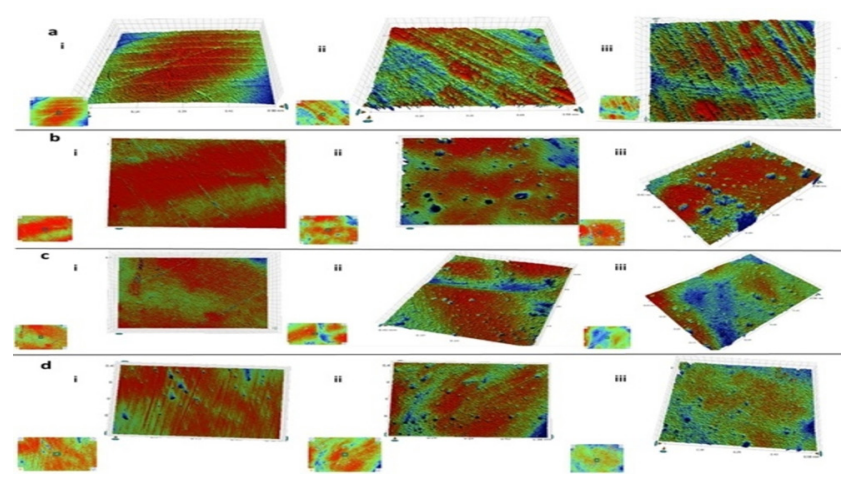

Fig. 2. 3D surface images of Filtek Bulk Fill composite treated with $C T(A)$, ExpT-A (B), ExpT-B (C), and ExpT-C (D), with the number of cycles: (i) 0, (ii) 5,000 and (iii) 10,000; red area represents high point, while blue area represents low point 


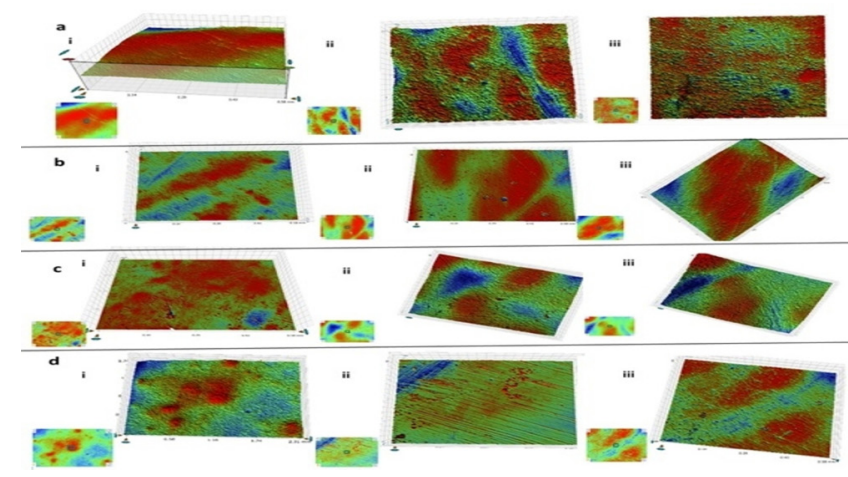

Fig. 3. 3D surface images of Filtek Z350 XT composite treated with CT (A), ExpT-A (B), ExpT-B (C), and ExpT-C (D), with the number of cycles: (i) 0, (ii) 5,000 and (iii) 10,000; red area represents high point, while blue area represents low point

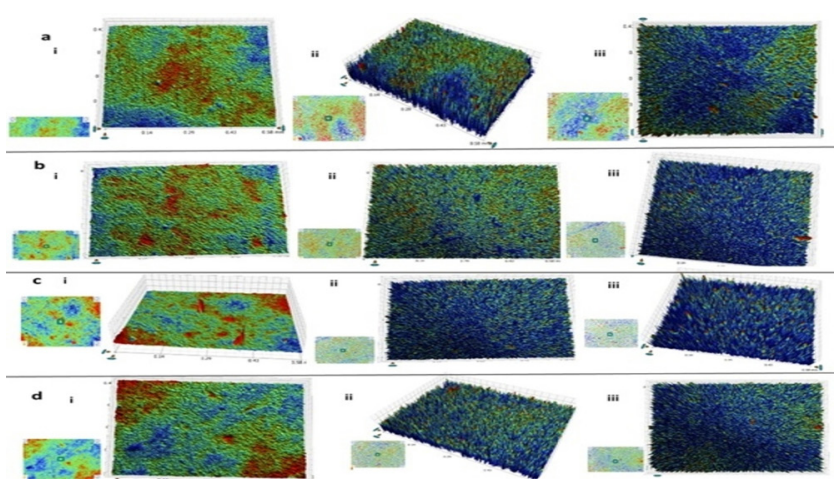

Fig. 4. 3D surface images of GC Fuji II LC composite treated with CT (A), ExpT-A (B), ExpT-B (C), and ExpT-C (D), with the number of cycles: (i) 0, (ii) 5,000 and (iii) 10,000; red area represents high point, while blue area represents low point

\section{Color stability measurement}

In terms of color stability, all samples showed an insignificant difference $(p \geq 0.05)$ as compared to the control and to the 3 experimental dentifrices for all the cycles - pre, post-5,000 and post-10,000. The values are given in Fig. 5.

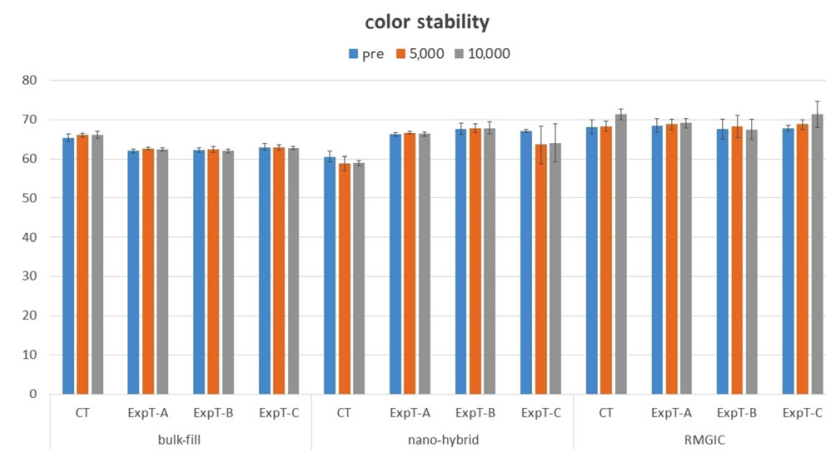

Fig. 5. Color stability measurements before and after the tooth brushing treatment

\section{Discussion}

The influence of dentifrices on the surface of restorations have been noticed and their effect has been linked to dentifrice ingredients. Components such as bioactive glass, calcium carbonate, $\mathrm{ZnO}, \mathrm{TiO}_{2}$, and other, which have the capability to influence the substratum surface, subsequently influence the characteristics of esthetic restorative materials. The dentifrices exerted a significant effect on the surface roughness when comparing the control and treated samples. The presence of active ingredients in the experimental dentifrices, i.e., $\mathrm{F}-\mathrm{BG}, \mathrm{TiO}_{2}$ and $\mathrm{ZnO}$, showed a significant effect. The effect with regard to the various concentrations of F-BG in the samples was insignificant. The presence of abrasive particles in the dentifrice is a factor that affects the surface roughness of the esthetic restoration. The surface roughness of esthetic restorations have been further linked on a deeper level to the size and type of the abrasive agent used. ${ }^{5}$

In another aspect, different behavior has been observed with respect to the composition of the restorative materials. The nano-hybrid composite has been

Table 3. Mean surface roughness values ( $R a$ ) of all esthetic restorative materials after 0; 5,000; and 10,000 cycles

\begin{tabular}{|c|c|c|c|c|}
\hline \multirow{2}{*}{ Groups } & \multirow{2}{*}{ Restorative materials } & \multicolumn{3}{|c|}{ Ra values [nm] and SD with regard to the number of cycles } \\
\hline & & 0 & 5,000 & 10,000 \\
\hline \multirow{3}{*}{$\mathrm{CT}$} & Filtek Bulk Fill & $34.60 \pm 11.01$ & $49.86 \pm 18.14$ & $43.85 \pm 19.81$ \\
\hline & Filtek Z350 XT & $39.60 \pm 3.11$ & $80.89 \pm 10.31$ & $82.63 \pm 16.85$ \\
\hline & GC Fuji II LC & $104.50 \pm 36.06$ & $1,747.75 \pm 131.41$ & $1,808.06 \pm 129.95$ \\
\hline \multirow{3}{*}{ ExpT-A } & Filtek Bulk Fill & $30.40 \pm 3.66$ & $110.80 \pm 13.22$ & $237.50 \pm 16.20$ \\
\hline & Filtek Z350 XT & $31.90 \pm 2.58$ & $43.50 \pm 18.76$ & $77.10 \pm 22.24$ \\
\hline & GC Fuji II LC & $104.80 \pm 26.2$ & $175.68 \pm 28.94$ & $243.65 \pm 65.34$ \\
\hline \multirow{3}{*}{ ExpT-B } & Filtek Bulk Fill & $30.40 \pm 10.61$ & $321.00 \pm 21.21$ & $399.00 \pm 22.45$ \\
\hline & Filtek Z350 XT & $32.40 \pm 15.05$ & $264.90 \pm 83.49$ & $351.40 \pm 85.28$ \\
\hline & GC Fuji II LC & $99.70 \pm 12.54$ & $383.35 \pm 52.94$ & $1,094.70 \pm 69.23$ \\
\hline \multirow{3}{*}{ ExpT-C } & Filtek Bulk Fill & $33.00 \pm 10.51$ & $83.09 \pm 17.55$ & $121.56 \pm 18.76$ \\
\hline & Filtek Z350 XT & $29.90 \pm 3.88$ & $66.88 \pm 18.20$ & $137.61 \pm 13.75$ \\
\hline & & $99.50 \pm 18.71$ & $474.90 \pm 77.31$ & $473.00 \pm 121.70$ \\
\hline
\end{tabular}

CT - control (commercial dentifrice); ExpT-A, ExpT-B, ExpT-C - experimental dentifrices; SD - standard deviation. 
noticed to present a smaller change in the surface roughness than the bulk-fill one. This difference is claimed to be due to the filler particles, which can be displaced, causing more surface exposure of the weak parts of the composite (the organic matrix). The distribution and size of the filler have an impact on the surface roughness. ${ }^{4,8}$ In this study, the resin-based composites showed an insignificant change in the micro-hardness values and less increase in the surface roughness as compared to RMGIC. The results were justified by the fact that composites have silane coupling agents, which bind the filler particles chemically with the resin matrix, and the same material accounts for their hydrolytic stability. ${ }^{13}$ The presence of zirconia and silica particles resulted in more resistance in terms of surface roughness; however, it was increased. Compared with micro-particles, the nano-particle-based composite showed relatively better results. The resin-modified glass-ionomer cement contained alumina-silicate particles, and their interaction with dentifrices caused more surface roughness and wear, and subsequently, the micro-hardness values changed.

Prior to the treatment, all samples were polished, because delivering a restoration which has well-polished, smooth surface gives the most favorable esthetic result, with less plaque accumulation. ${ }^{3,24}$ It is reported that $0.2 \mu \mathrm{m}$ of surface roughness is a critical value in the retention of bacteria, while surface roughness of $0.3 \mu \mathrm{m}$ can be detected by the tongue. ${ }^{3,25}$ In this study, the surface roughness result for Filtek Bulk Fill after 5,000 cycles of brushing with ExpT-A and ExpT-C was favorable, with a value of $<0.2 \mu \mathrm{m}$. However, the Ra value after proceeding to 10,000 cycles of brushing with the same experimental toothpastes (ExpT-A and ExpT-C) increased to $>0.2 \mu \mathrm{m}$, though not exceeding $0.3 \mu \mathrm{m}$. The Ra values for Filtek Z350 XT after 5,000 cycles with ExpT-A and ExpT-C were $<0.2 \mu \mathrm{m}$. After completing 10,000 cycles with ExpT-C, the Ra value remained below $0.2 \mu \mathrm{m}$, whereas with ExpT-A, the Ra value increased to $>0.2 \mu \mathrm{m}$, though not exceeding $0.3 \mu \mathrm{m}$.

In assessing the effect of the dentifrice on the microhardness of the restoration, one should take into consideration the dentifrice $\mathrm{pH}$. It is reported that dentifrices with natural or acidic $\mathrm{pH}$ values cause more micro-hardness changes than alkaline ones. ${ }^{26}$ An analysis of $\mathrm{pH}$ of the experimental dentifrices is beyond the scope of the present study. However, it will be published later. In our previous study, it was observed that $\mathrm{pH}$ of F-BG (5 mol\%) was 8.0 in deionized water and upon aging it did not change significantly. ${ }^{22}$ It is anticipated that the presence of alkaline contents (both F-BG and $\mathrm{ZnO}$ nanoparticles) as active agents made these experimental dentifrices alkaline. Therefore, an insignificant difference was observed related to the micro-hardness of RBCs. The presence of F-BG in an aqueous medium can lead to the breakage of bonds within a bioactive glass network, as the network breakage reaction is highly sensitive to the attack of molecular water. This breakage can enhance the dissolution rate of bioactive glass, and subsequently, the effect on the properties of restorative materials. It may leave deposits on the surface of these materials, and alter the physical and mechanical properties. It has been reported that the presence of fluoride in bioactive glass results in slower dissolution as compared to bioactive glass alone. ${ }^{27}$ However, the dissolution of bioactive glasses is a complex process and there is still no complete consensus on the basic mechanism.

Limited studies have been conducted to evaluate the color stability of esthetic materials after using dentifrices. Previously, it was reported that along with the application of whitening dentifrices, significant changes in color stability were observed. ${ }^{11}$ However, this study showed insignificant changes with regard to the application of the commercial and experimental dentifrices. Regarding the effects of the commercial and experimental dentifrices on the samples, no difference was observed in color stability, surface roughness or micro-hardness. However, more roughness and change in the microhardness values were noticed along with the increase in the concentration of the active ingredient in the experimental dentifrices. On the basis of these evaluations in the current study, it is suggested that among these toothpaste groups, the experimental dentifrices with 3.5\% F-BG and 3\% $\mathrm{ZnO}$ as active ingredients showed better performance in terms of micro-hardness and surface roughness. It is also expected that these active ingredients have the potential to reduce demineralization and hypersensitivity, and increase the antibacterial properties of the toothpaste. However, these characteristics are beyond the scope of the present study and will be presented later.

\section{Conclusions}

It appears from this study that introducing experimental dentifrices containing fluoride-based bioactive glass and $\mathrm{ZnO}$ oxide have a safe effect on esthetic restorations. This study is considered to be a pioneer in evaluating the effects of bioceramic and metal oxide-based experimental dentifrices on esthetic restorations. Future studies are needed with patient involvement, for better simulation of normal circumstances, to give a more precise assessment of experimental dentifrices.

\section{ORCID iDs}

Abdulelah Ali AlSubaie (D) https://orcid.org/0000-0002-5312-7166 Zenab Sarfraz (D) https://orcid.org/0000-0001-6449-2882 Abdulhadi Ahmed AIAli (D) https://orcid.org/0000-0003-1472-3667 Abdulmohsen Essa AlEssa (i) https://orcid.org/0000-0003-1520-5554 Hassan Ali AlSubaie (D) https://orcid.org/0000-0003-3306-2913 Asma Tufail Shah (D https://orcid.org/0000-0001-9624-1842 Abdul Samad Khan (D) https://orcid.org/0000-0002-2165-800X 


\section{References}

1. Khalaf $M E$, Alomari QD, Omar R. Factors relating to usage patterns of amalgam and resin composite for posterior restorations - a prospective analysis. J Dent. 2014;42(7):785-792.

2. Bohaty BS, Ye Q, Misra A, Sene F, Spencer P. Posterior composite restoration update: Focus on factors influencing form and function. Clin Cosmet Invesig Dent. 2013;5:33-42.

3. da Costa J, Adams-Belusko A, Riley K, Ferracane JL. The effect of various dentifrices on surface roughness and gloss of resin composites. J Dent. 2010;38(Suppl 2):e123-e128.

4. Liu J, Zhang SS, Zheng SG, Xu T, Si Y. Oral health status and oral health care model in China. Chin J Dent Res. 2016;19(4):207-215.

5. Roselino Lde M, Chinelatti MA, Alandia-Román CC, Pires-de-Souza Fde $C$. Effect of brushing time and dentifrice abrasiveness on color change and surface roughness of resin composites. Braz Dent J. 2015;26(5):507-513.

6. Bezgin T, Özer L, Tulga Öz F, Özkan P. Effect of toothbrushing on color changes of esthetic restorative materials. J Esthet Restor Dent. 2015;27(Suppl 1):S65-S73.

7. Roselino Lde M, Cruvinel DR, Chinelatti MA, Pires-de-Souza Fde C. Effect of brushing and accelerated ageing on color stability and surface roughness of composites. J Dent. 2013;41(Suppl 5):e54-e61.

8. Faria AC, Bordin AR, Pedrazzi V, Rodrigues RC, Ribeiro RF. Effect of whitening toothpaste on titanium and titanium alloy surfaces. Braz Oral Res. 2012;26(6):498-504.

9. Alandia-Román CC, Cruvinel DR, Sousa AB, Pires-de-Souza Fde C Panzeri $\mathrm{H}$. Effect of cigarette smoke on color stability and surface roughness of dental composites. J Dent. 2013;41(Suppl 3):e73-e79.

10. Wang L, Garcia FC, Amarante de Araújo P, Franco EB, Mondelli RF. Wear resistance of packable resin composites after simulated toothbrushing test. J Esthet Restor Dent. 2004;16(5):303-314.

11. Roopa KB, Basappa N, Prabhakar AR, Raju OS, Lamba G. Effect of whitening dentifrice on micro hardness, colour stability and surface roughness of aesthetic restorative materials. J Clin Diagn Res. 2016;10(3):ZC6-ZC11.

12. Mahmood A, Mneimne M, Zou LF, Hill RG, Gillam DG. Abrasive wear of enamel by bioactive glass-based toothpastes. Am J Dent 2014;27(5):263-267.

13. Hamouda IM. Effects of various beverages on hardness, roughness, and solubility of esthetic restorative materials. J Esthet Restor Dent 2011;23(5):315-322

14. Wang $Y$, Mei $L$, Gong $L$, et al. Remineralization of early enamel caries lesions using different bioactive elements containing toothpastes: An in vitro study. Technol Health Care. 2016;24(5):701-711.

15. Momoi $Y$, Hirosaki K, Kohno A, McCabe J. In vitro toothbrushdentifrice abrasion of resin-modified glass ionomers. Dent Mater. 1997;13(2):82-88.

16. Khoroushi $M$, Kachuie M. Prevention and treatment of white spot lesions in orthodontic patients. Contemp Clin Dent. 2017;8(1):11-19.

17. Sufi F, Hall C, Mason S, Shaw D, Milleman J, Milleman K. Efficacy of an experimental toothpaste containing $5 \%$ calcium sodium phosphosilicate in the relief of dentin hypersensitivity: An 8-week randomized study (Study 2). Am J Dent. 2016;29(2):101-109.

18. Lee BS, Tsai HY, Tsai YL, Lan WH, Lin CP. In vitro study of DP-bioglass paste for treatment of dentin hypersensitivity. Dent Mater J. 2005;24(4):562-569.

19. Walsh T, Worthington HV, Glenny AM, Appelbe P, Marinho VC, Shi X. Fluoride toothpastes of different concentrations for preventing dental caries in children and adolescents. Cochrane Database Syst Rev. 2010;20(1):007868.

20. Lynch E, Brauer DS, Karpukhina N, Gillam DG, Hill RG. Multi-component bioactive glasses of varying fluoride content for treating dentin hypersensitivity. Dent Mater. 2012;28(2):168-178.

21. Takatsuka T, Tanaka K, lijima Y. Inhibition of dentine demineralization by zinc oxide: In vitro and in situ studies. Dent Mater. 2005;21(12):1170-1177.

22. Gul H, Zahid S, Zahid S, Kaleem M, Khan AS, Shah AT. Sol-gel derived fluoride-doped bioactive glass powders: Structural and long-term fluoride release/pH analysis. J Non Cryst Solid. 2018;498:216-222.

23. Ahtzaz S, Nasir M, Shahzadi L, et al. A study on the effect of zinc oxide and zinc peroxide nanoparticles to enhance angiogenesis -pro-angiogenic grafts for tissue regeneration applications. Mater Design. 2017;132:409-418.
24. Hotta $M$, Hirukawa $H$, Aono $M$. The effect of glaze on restorative glass-ionomer cements. J Oral Rehabil. 1995;22(3):197-201.

25. Jones CS, Billington RW, Pearson GJ. The in vivo perception of roughness of restorations. Br Dent J. 2004;196(1):42-45.

26. Nainan MT, Balan AK, Sharma R, Thomas SS, Deveerappa SB. The comparison of the effects of different whitening toothpastes on the micro hardness of a nano hybrid composite resin. J Conserv Dent. 2014;17(6):550-554.

27. Shaharyar Y, Wein E, Kim JJ, et al. Structure-solubility relationships in fluoride-containing phosphate based bioactive glasses. J Mater Chem B. 2015;3(48):9360-9373. 
